\title{
Stereoisomeric Analysis of 6,10,14-Trimethylpentadecan-2-ol and the Corresponding Ketone in Wing Extracts from African Bicyclus Butterfly Species
}

\author{
E. Hedenström • E. A. Wallin • J. Andersson • J. Bång • \\ H.-L. Wang • C. Löfstedt • O. Brattström • P. Baquet
}

Received: 14 July 2014 /Revised: 28 October 2014 / Accepted: 12 November 2014 /Published online: 20 December 2014

(C) Springer Science+Business Media New York 2014

\begin{abstract}
Gas chromatography (GC) and mass spectrometry (MS) were used to determine the stereoisomeric compositions of 6,10,14-trimethylpentadecan-2-ol and 6,10,14trimethylpentadecan-2-one in wing extracts from 17 Bicyclus butterfly species from different regions of Africa. All samples were purified using solid phase extraction (SPE). Since some species contained both alcohol and ketone, these were separated and the ketone was reduced to the alcohol before analysis as either (R)-trans-chrysanthemoyl or $(S)$-2acetoxypropionyl esters. A novel asymmetric synthesis was developed for a reference mixture of $(2 R / S, 6 S, 10 R)-6,10,14$ trimethylpentadecan-2-ol with known composition of the eight stereoisomers. The mixture then was used as the $(R)$ trans-chrysanthemoyl esters to correlate each of the eight gas chromatographic peaks to a specific stereoisomer of the extracted wing compounds. Seven butterfly species showed $(2 R$, $6 R, 10 R$ )-configuration of the alcohol, four species contained minute amounts of alcohol too small to determine the stereochemistry, nine species showed $(6 R, 10 R)$-configuration of the
\end{abstract}

Electronic supplementary material The online version of this article (doi:10.1007/s10886-014-0539-5) contains supplementary material, which is available to authorized users.

E. Hedenström $(\varangle) \cdot$ E. A. Wallin · J. Andersson · J. Bång Eco-Chemistry, Department of Chemical Engineering, Mid Sweden University, 85170 Sundsvall, Sweden

e-mail: erik.hedenstrom@miun.se

H.-L. Wang • C. Löfstedt

Department of Biology, Lund University, Sölvegatan 37, 223

62 Lund, Sweden

O. Brattström

Department of Zoology, Cambridge University, Cambridge, UK

P. Baquet

Evolutionary Ecology and Genetics group, Biodiversity Research Centre, Earth and Life Institute, Académie Louvain, Croix du Sud 4, 1348 Louvain-la-Neuve, Belgium ketone, and one species contained minute amounts of ketone too small to determine the stereochemistry. No other stereoisomers of alcohol or ketone could be detected in the extracts, and the quantities of the compounds in the wing extracts varied from 5 to $900 \mathrm{ng}$ per sample for each species.

Keywords Asymmetric synthesis · GC/MS · 6,10,14-Trimethylpentadecan-2-one · Wing compounds . Stereoisomers

\section{Introduction}

Pheromones and other semiochemicals found in nature are often chiral compounds that have one or more stereogenic centers and can exist as two or more stereoisomers. Consequently, the biological functions of the different stereoisomers need to be considered since in some cases small amounts of stereoisomers might act as synergists or antagonists in biological assays. The importance of the optical purity of such volatile organic compounds used for communication within a species is demonstrated by the sex pheromone found in the pine sawfly species Neodiprion sertifer. Female $N$. sertifer use the acetate of ( $2 S, 3 S, 7 S)$-3,7-dimethylpentadecan-2-ol as a sex pheromone. However, even a small amount $(<0.2 \%)$ of the $(2 S$, $3 R, 7 R$ )-stereoisomer inhibits the attractiveness (Anderbrant 1999; Anderbrant et al. 2000). This example emphasizes the need for analytical methods that effectively separate stereoisomers of biologically-active compounds (Bång et al. 2011, 2012) in order to interpret and understand the results of bioassays.

Another example of a bioactive secondary alcohol that can exist as eight stereoisomers is 6,10,14-trimethylpentadecan-2-ol that is used as sex pheromone by pest insects such as the rice moth, Corcyra cephalonica, the African sugar-cane borer moth, Eldana saccharina, and the oil palm bunch moth, Tirathaba mundella (Burger et al. 1993; Hall et al. 1987; Mori et al. 1991; 
Sasaerila et al. 2003). The same compound also is produced by many African butterfly species of the genus Bicyclus (Nieberding et al. unpublished information and results in this paper) and in particular, Bicyclus anynana where 6,10,14trimethylpentadecan-2-ol is a confirmed pheromone component together with (Z)-9-tetradecen-1-ol and hexadecanal (Nieberding et al. 2008). Recently the stereochemistry of the wing compound was verified as $(2 R, 6 R, 10 R)-6,10,14$ trimethylpentadecan-2-ol (Nieberding et al. 2012). So far there are no reports of $(2 R, 6 R, 10 R)-6,10,14$-trimethylpentadecan-2ol in other Bicyclus species but 6,10,14-trimethylpentadecan-2ol and the corresponding ketone have been found in several other species, and differences in the stereochemistry of these compounds may potentially contribute to species specificity.

Gas chromatography (GC) with mass spectrometry (MS) has been the conventional method for analyzing derivatized secondary alcohols such as 6,10,14-trimethylpentadecan-2-ol in extracts from male $B$. anynana butterflies (Nieberding et al. 2008). The general approach to separate stereoisomers of secondary alcohols is to use pre-column derivatization, resulting in chiral or non-chiral derivatives in combination with chiral or non-chiral columns. However, combinations of different derivatives and columns often have been necessary to separate all the stereoisomers satisfactorily (Bång et al. 2011; Bergström et al. 1995; Wassgren et al. 1992). Preparation of all eight stereoisomers individually is normally necessary to be able to determine the retention time of each stereoisomer, and this involves laborious and time consuming synthetic work. Thus, to be able to screen different species efficiently for the composition of their wing volatile blend and the stereoisomeric compositions of 6,10,14trimethylpentadecan-2-ol and 6,10,14-trimethylpentadecan-2one, we developed a novel synthetic route for a reference mixture of the alcohol with a known composition of stereoisomers in order to determine the GC-retention time for each stereoisomer. In this study, we used GC/MS to determine the stereoisomeric composition of 6,10,14-trimethylpentadecan-2ol and 6,10,14-trimethylpentadecan-2-one in wing extracts from seventeen species of African Bicyclus butterflies. We improved the conditions for the GC/MS analysis of $(R)$-transchrysanthemoyl (Bång et al. 2012) and (S)-2-acetoxypropionyl derivatives (Bång et al. 2011) of 6,10,14-trimethylpentadecan2-ol, including the identification of the elution order of each stereoisomer of the alcohol.

\section{Methods and Materials}

Chemicals The solvents used were of spectrophotometric grade or higher and purchased from Sigma-Aldrich, Schnelldorf, Germany. (3R)-3,7-Dimethyloct-6-enoic acid, (S)-2-acetoxypropionyl chloride (Fluka, puriss.), pentadecan2-one were purchased from Sigma-Aldrich and the pentadecan-2-ol came from The Sigma-Aldrich Library of Rare Chemicals, Milwaukee WI, USA.

Synthesis The $(2 S, 6 R / S, 10 R / S)$ - and $(2 R, 6 R / S, 10 R / S)-6,10$, 14-trimethylpentadecan-2-ol mixtures were synthesized from ( $2 E, 7 R / S, 11 R / S)$-3,7,11,15-tetramethyl-2-hexadecen-1-ol (phytol) following the protocol in Nieberding et al. (2008). By applying the same protocol but starting from $(2 E, 7 R, 11 R)$ phytol the pure stereoisomers of $(2 S, 6 R, 10 R)-6,10,14$ trimethylpentadecan-2-ol and $(2 R, 6 R, 10 R)-6,10,14$ trimethylpentadecan-2-ol were synthesized (Nieberding et al. 2012).

A novel asymmetric synthetic strategy was developed in order to produce a mixture of 6,10,14-trimethylpentadecan-2-ol isomers with known isomeric composition (Scheme 1), as described in the Results section and Supplementary Material.

Insect Extracts We analyzed the volatile chemicals produced in the butterfly wings from a total of seventeen Bicyclus species found in different regions of Africa. For each species, the wing samples were collected from three male and two female individuals. The wings were dissected into several pieces according to the androconia location and the pieces extracted separately in $1.5 \mathrm{ml}$ glass vials with $100 \mu \mathrm{l}$ of redistilled $n$-heptane containing $1 \mathrm{ng} \mu \mathrm{l}^{-1}$ of $(Z)$-8-tridecen$1-y l$ acetate as internal standard. For samples of whole wings, the hindwing and forewing sections were extracted separately

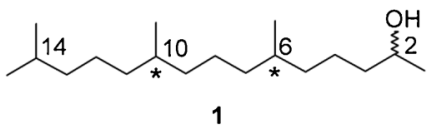

(2R/S,6S, 10R)-6, 10,14-trimethylpentadecan-2-ol with known stereisomeric purity $R / S$ at position $250 / 50$,

at position $675 / 25$ and at position $1057 / 43$
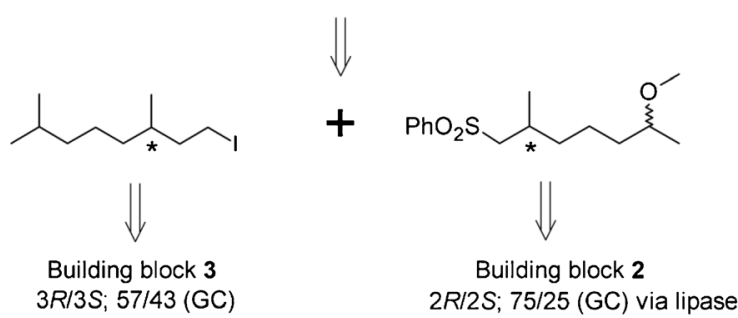

3R/3S: $57 / 43$ (GC) catalysed diastereoselection<smiles>C=C=C</smiles><smiles>CC(C)=CCC[C@H](C)CC(=O)O</smiles>

3,7-Dimethyloct-6-enoic acid $3 R / 3 S, 57 / 43$ (GC) from the chiral pool

Scheme 1 Retrosynthetic analysis for a stereoisomeric mixture of $(2 R /$ $S, 6 S, 10 R)-6,10,14$-trimethylpentadecan-2-ol (1) containing all eight isomers with known stereoisomeric composition 
in $300 \mu \mathrm{l}$ of $n$-heptane containing the same internal standard at a concentration of $0.33 \mathrm{ng} \mathrm{Il}^{-1}$.

Analysis of Crude Extracts Initial screening was performed to establish the content of 6,10,14-trimethylpentadecan-2-ol and the corresponding ketone in 32 Bicyclus species (Nieberding et al. unpublished data) in order to be able to select the seventeen species that contained relatively high amounts of the target compounds for stereochemical analysis. Partial and whole wing extracts from the selected species then were analyzed on an Agilent 6890 N GC (Agilent, Walbronn, Germany) with a polar FactorFOUR VF-23 ms column $\left(30 \mathrm{~m} \times 0.25 \mathrm{~mm}\right.$ i.d., $\mathrm{d}_{\mathrm{f}}=0.25 \mu \mathrm{m}$ Varian, Palo Alto, CA USA) and an HP 5973 MS detector (Agilent) in electron impact (EI) ionization mode. The carrier gas was helium $\left(1 \mathrm{ml} \mathrm{min}{ }^{-1}\right) ; 1 \mu \mathrm{l}$ of the sample was injected splitless, the injector temperature was $250{ }^{\circ} \mathrm{C}$, and the auxilliary temperature was $280{ }^{\circ} \mathrm{C}$. For identification of the alcohol and ketone in crude extracts, the full scan mode was used, and the column temperature increased from $50^{\circ} \mathrm{C}$ at $10^{\circ} \mathrm{C} \mathrm{min}^{-1}$ up to $230{ }^{\circ} \mathrm{C}$ and held at $230{ }^{\circ} \mathrm{C}$ for $10 \mathrm{~min}$.

Purification of Insect Extracts Two internal standards (IS), pentadecan-2-one (73-1099 ng) and pentadecan-2-ol (90$1017 \mathrm{ng}$ ), were added to the crude hexane extracts from each species in amounts adjusted to match the amount of the analyzed compound in each sample. Each extract then was purified by liquid chromatography (LC) using gradient elution stepwise with $1-11 \%$ ethyl acetate in pentane in steps of $1 \%$ $(0.75 \mathrm{ml})$ on a $500 \mathrm{mg}$ Strata SI-1 Silica Teflon coated solid phase column (Skandinaviska Genetec AB, Västra Frölunda, Sweden). The collected ketone fractions (4-8; $0.75 \mathrm{ml})$ were pooled and reduced to alcohol with $\mathrm{LiAlH}_{4}$ before derivatization, and were then analyzed as described below. The alcohol fractions (9-11) were pooled and after derivatization they were also analyzed as described below. The internal standards were used both as a control of the purification method and for quantification of ketone and alcohol applying the response factor ratios of $1: 1$.

Derivatisation of Purified Extracts To determine the stereochemistries of the 6,10,14-trimethylpentadecan-2-ol and 6, 10,14-trimethylpentadecan-2-one, the pooled alcohol fraction was derivatized with $(R)$-trans-chrysanthemoyl chloride according to Bång et al. (2012) or with (S)-2-acetoxypropionyl chloride according to Bång et al. (2011). The pooled ketone fraction with 6,10,14-trimethylpentadecan-2-one was first reduced to alcohol with $\mathrm{LiAlH}_{4}$ before derivatization, as described above. When the target compounds were present in low concentration, the $(S)$-2-acetoxypropionyl chloride method was used, otherwise the extracts were derivatized with $(R)$-trans-chrysanthemoyl chloride.
Stereochemical Analysis Improved conditions were developed for separation of (R)-trans-chrysanthemoyl (Bång et al. 2012) and (S)-2-acetoxypropionyl derivatives (Bång et al. 2011) of 6,10,14-trimethylpentadecan-2-ol in GC/MS analyses. Equipment for the GC/MS analyses was as above. The selective ion monitoring mode (SIM) $(m / z 105,115,133,210$, 252 ) was used for identification of the $(S)$-2-acetoxypropionyl derivatives, and the column temperature was increased from $50{ }^{\circ} \mathrm{C}$ at $10{ }^{\circ} \mathrm{C} \min ^{-1}$ up to $110{ }^{\circ} \mathrm{C}$, from $110{ }^{\circ} \mathrm{C}$ by $0.02{ }^{\circ} \mathrm{C} \mathrm{min}{ }^{-1}$ up to $116^{\circ} \mathrm{C}$, and from $116^{\circ} \mathrm{C}$ by $10{ }^{\circ} \mathrm{C}$ min ${ }^{1}$ up to $230^{\circ} \mathrm{C}$, and held at $230^{\circ} \mathrm{C}$ for $10 \mathrm{~min}$. For identification of $(R)$-trans-chrysanthemoyl derivatives, SIM $(\mathrm{m} / z 123$, 124,153 , and 168) was used and the column temperature was increased from $50{ }^{\circ} \mathrm{C}$ by $10{ }^{\circ} \mathrm{C} \min ^{-1}$ up to $100{ }^{\circ} \mathrm{C}$, from $100{ }^{\circ} \mathrm{C}$ by $0.1{ }^{\circ} \mathrm{C} \min ^{-1}$ to $140{ }^{\circ} \mathrm{C}$, and from $140{ }^{\circ} \mathrm{C}$ by $10^{\circ} \mathrm{C} \min ^{-1}$ up to $230{ }^{\circ} \mathrm{C}$ and held at $230^{\circ} \mathrm{C}$ for $10 \mathrm{~min}$.

The enantiomeric compositions of intermediates in the synthesis were determined by enantioselective GC analysis using a $\beta$-dex225 column $\left(30 \mathrm{~m} \times 0.25 \mathrm{~mm}, \mathrm{~d}_{\mathrm{f}}=0.25\right.$; Supelco), operated isothermally at $70{ }^{\circ} \mathrm{C}$.

\section{Results and Discussion}

Synthesis A novel asymmetric synthesis strategy was developed in order to produce a mixture of 6,10,14trimethylpentadecan-2-ol stereoisomers with known isomeric composition (Scheme 1), and detailed procedures are described in the Supplementary Material.

Building block 2 was obtained in ten steps from commercially available 6-methyl-5-hepten-2-one. This was reduced to the alcohol with lithium aluminum hydride in ether, and the alcohol was methylated with sodium hydride and methyl iodide. Allylic oxidation was performed with tert-BuOOH and $\mathrm{SeO}_{2}$ (Salimova et al. 2003; Umbreit and Sharpless 1977), and the saturated compound was obtained by hydrogenation with Ra-Ni (Högberg et al. 1992; Shibata et al. 2002). The alcohol was oxidized to the 6-methoxy-2methylheptanoic acid with Jones reagent (Nagamitsu et al. 1996) using iso-propanol in excess to react all the chromium reagent.

The key stereoselective step in the synthesis of building block 2 was the lipase-catalyzed resolution of this acid. In earlier syntheses, we successfully used lipase-catalyzed resolution of 2-methylcarboxylic acids (See for example Hedenström et al. 2002). Thus, the 6-methoxy-2methylheptanoic acid was esterified with 2,2-dimethylpropanol under catalysis of Candida rugosa lipase (CRL) immobilized on Accurel in isooctane (Sabbani et al. 2006) to obtain the remaining $(R)$-acid in optical purity of $2 R / 2 S 75: 25$, as measured by GC analysis on the $\beta-\operatorname{dex} 225$ column, at a conversion of $30 \%$. The (2R)-6-methoxy-2-methylheptanoic 
acid obtained was reduced to the alcohol using lithium aluminum hydride in ether, and the product had the same enantiomeric purity as the starting acid. The alcohol then was transformed to (2R)-1-iodo-6-methoxy-2-methylheptane via a tosylate (Burns et al. 1997) and the iodo-compound was reacted with $\mathrm{PhSO}_{2} \mathrm{Na}$ in dry DMF (Kandula and Kumar 2006; Nakamura and Mori 2000) to furnish the sulfone building block 2 (Scheme 2).

Building block 3 was obtained in three steps from commercially-available $(R)$-3,7-dimethyloct-6-enoic acid $((R)-(+)$-citronellic acid; SigmaAldrich) which was reduced to the alcohol with simultaneous reduction of the double bond (Ashby and Lin 1978). The stereoisomeric purity of the 3,7dimethyloct-6-enoic acid and the corresponding alcohol was determined by enantioselective GC analysis as $3 R / 3 S 57: 43$. (R)-3,7-Dimethyloctan-1-ol was transformed to the corresponding iodide via a tosylate (Enders and Schüsseler 2002; Kimura et al. 2001) (Scheme 3).

Alkylation of the anion derived from $\mathbf{2}$ with the iodide $\mathbf{3}$ resulted in a product with the desired carbon skeleton which yielded the methyl-protected alcohol after sulfone reduction (Nakamura and Mori 2000; Shibata et al. 2002). The methoxy ether was subjected to oxidative cleavage, and the ketone obtained was reduced to the required reference mixture of eight stereoisomers of $(2 R / S, 6 S, 10 R)-6,10,14$ trimethylpentadecan-2-ol (1) (Scheme 4).

GC/MS Analysis of Stereoisomers of 6,10,14Trimethylpentadecan-2-ol The different reference mixtures were derivatized as $(R)$-trans-chrysanthemoyl and $(S)$-2acetoxypropionyl esters, and the $(R)$-trans-chrysanthemoyl

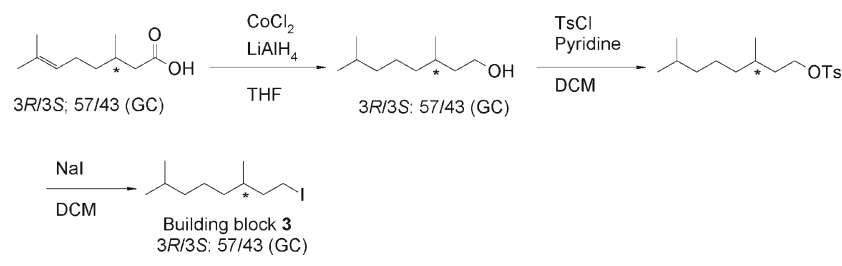

Scheme 3 Synthesis of building block 3 with known enantiomeric purity

esters resulted in better separation on GC/MS analysis (See Figs. 1 and 2). Thus, the first derivatization and analytical method was used to verify the GC elution order of the eight stereoisomers of 6,10,14-trimethylpentadecan-2-ol.

By comparing the stereoisomeric ratio of the synthetic reference alcohol $(2 R / S, 6 S, 10 R)-6,10,14$-trimethylpentadecan2-ol (1) calculated from the stereoisomeric purity of building blocks (See Table 1) with the relative peak area obtained by GC/MS analysis of the mixture after derivatization with $(R)$ trans-chrysanthemoyl (Fig. 1a), we concluded the elution order from the GC-column of the eight stereoisomers to be; $(2 S, 6 R, 10 S):(2 S, 6 R, 10 R):(2 S, 6 S, 10 R):(2 S, 6 S, 10 S):$ $(2 R, 6 S, 10 R):(2 R, 6 S, 10 S):(2 R, 6 R, 10 S):(2 R, 6 R, 10 R)$.

We previously reported (Nieberding et al. 2008) that when applying a lipase catalyzed stereoselective acylation of the eight-component stereoisomeric mixture of $(2 R / S, 6 R / S$, $10 R / S)$-6,10,14-trimethylpentadecan-2-ol, it was possible to isolate $(2 S, 6 R / S, 10 R / S)-6,10,14$-trimethylpentadecan-2-ol and $(2 R, 6 R / S, 10 R / S)-6,10,14$-trimethylpentadecan-2-ol as separate, four-component stereoisomeric mixtures. After applying the same derivatization and analytical method to these two reference mixtures, we confirmed the four-component mixture of $(2 S, 6 R / S, 10 R / S)$-6,10,14-trimethylpentadecan-
Scheme 2 Synthesis of building block 2 with known stereoisomeric purity

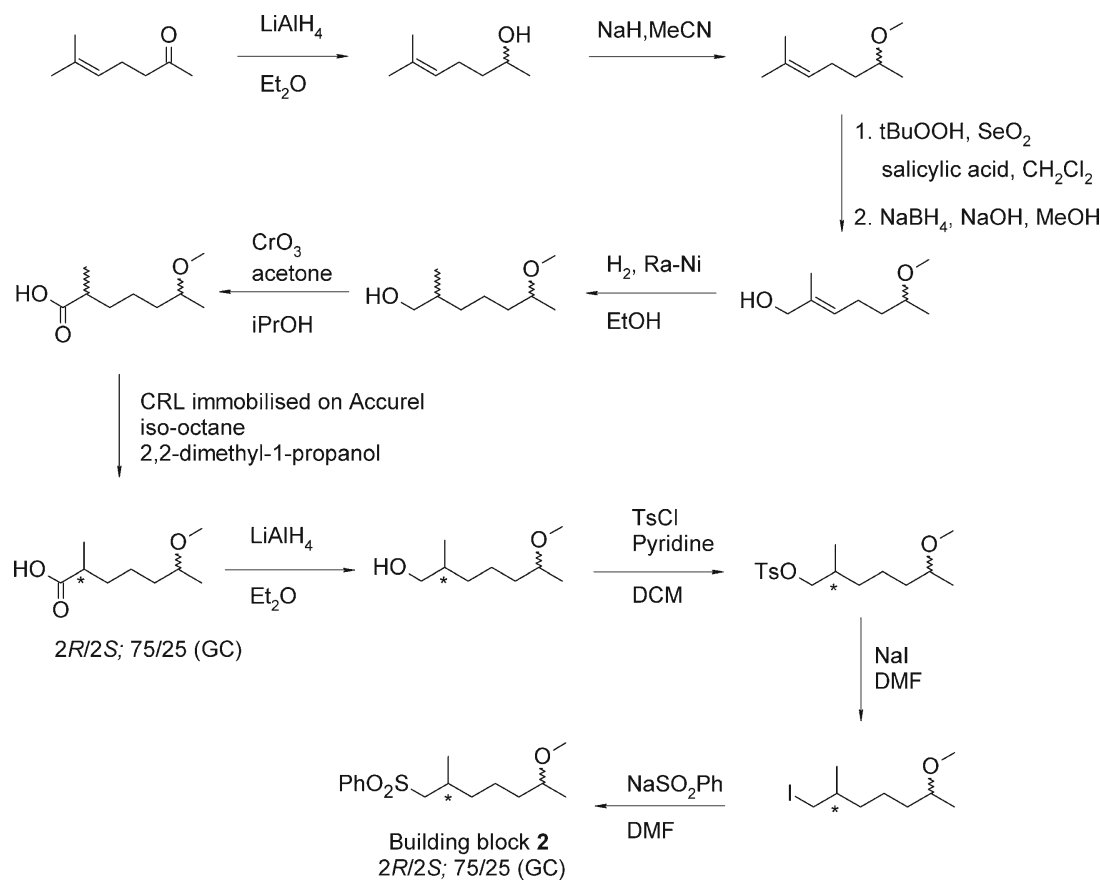


Scheme 4 Synthesis of $(2 R /$ $S, 6 S, 10 R)-6,10,14-$

trimethylpentadecan-2-ol (1) with known stereoisomeric

composition by coupling the two building blocks $\mathbf{2}$ and $\mathbf{3}$

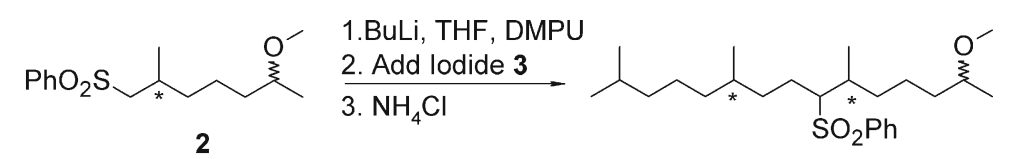

2

Li, EtNH
THF<smiles></smiles><smiles>CCOCC</smiles>

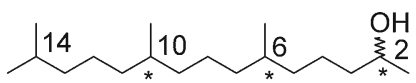

1

(2R/S,6S, 10R)-6,10,14-Trimethylpentadecan-2-ol with known stereoisomeric purity $R / S$ at position $250 / 50$, at position $675 / 25$ and at position $1057 / 43$ 2-ol eluted before the four-component mixture of $(2 R$, $6 R / S, 10 R / S$ )-6,10,14-trimethylpentadecan-2-ol (Fig. 1b and c, also reported in Nieberding et al. 2008). Two other synthetic reference mixtures i.e., the $2 R / S, 6 R, 10 R)-6,10$,
Fig. 1 GC/MS chromatograms of synthetic references a) $(2 R / S, 6 S, 10 R)-6,10,14-$

trimethylpentadecan-2-ol (1) with known stereoisomeric composition, b) $(2 R, 6 R / S, 10 R / S)$ mixture of four stereoisomers, $\mathbf{c})$ $(2 S, 6 R / S, 10 R / S)$-mixture of four stereoisomers, d) $(2 R / S, 6 R, 10 R)$ mixture of two stereoisomers, $\mathbf{e})$ pure $(2 R, 6 R, 10 R)$-stereoisomer. All samples were derivatized with (R)-trans-chrysanthemoyl chloride and analyzed on a FactorFOUR VF-23 ms column a

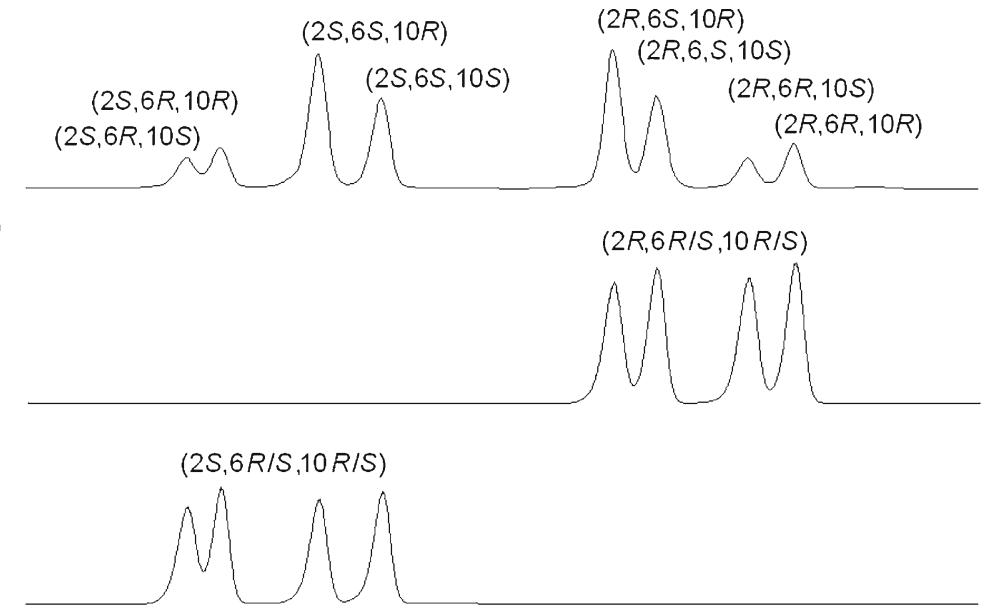

d $(2 S, 6 R, 10 R)$

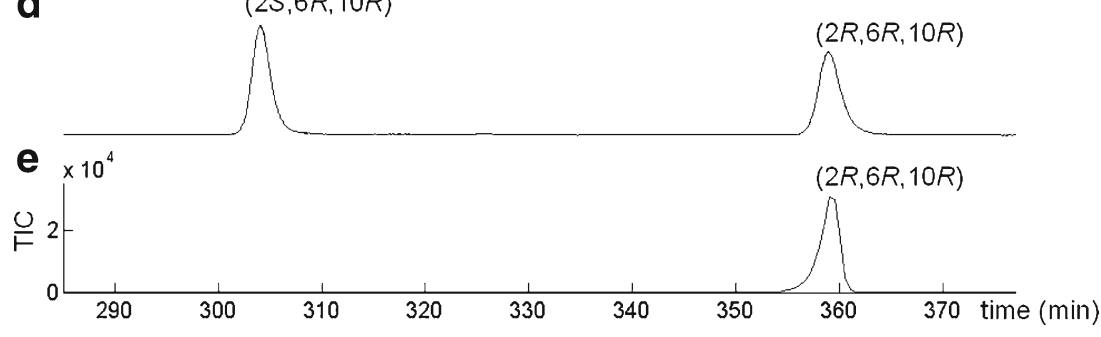


Fig. 2 GC/MS chromatograms of synthetic references a) $(2 R /$ $S, 6 R / S, 10 R / S)-6,10,14-$ trimethylpentadecan-2-ol an eight stereoisomeric mixture, $\mathbf{b})$ $(2 R, 6 R / S, 10 R / S)$-mixture of four stereoisomers, $\mathbf{c}$ ) $(2 S, 6 R / S, 10 R / S)$-mixture of four stereoisomers, d) pure $(2 R, 6 R, 10 R)$-stereoisomer, and $\mathbf{e})$ pure $(2 S, 6 \mathrm{R}, 10 R)$-stereoisomer. All samples were derivatized with $(S)$-2-acetoxypropionyl chloride and analyzed on a FactorFOUR VF-23 ms column a

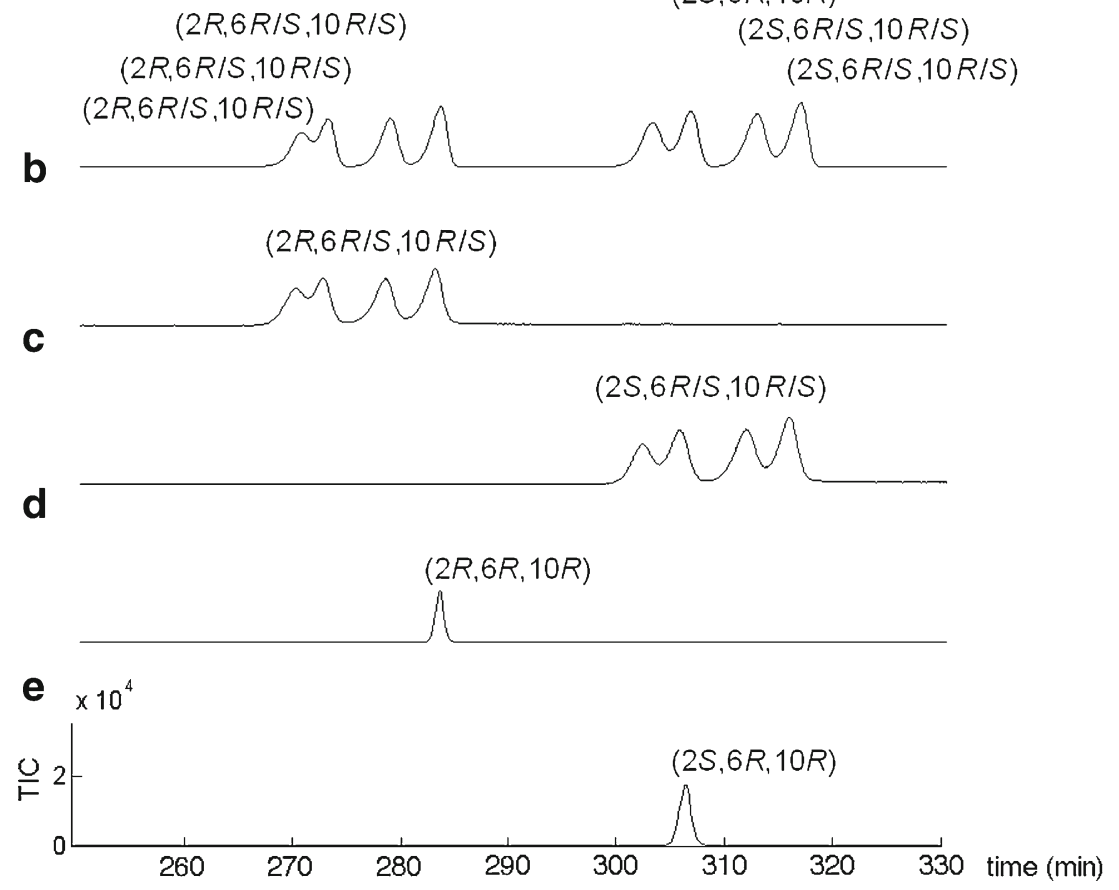

14-trimethylpentadecan-2-ol and the stereoisomerically pure $(2 R, 6 R, 10 R)-6,10,14$-trimethylpentadecan-2-ol, also were derivatized and analyzed by the same method (Fig. 1d and e). The analytical result obtained further strengthened the proposed elution order shown in Table 1.

The $(2 S, 6 R / S, 10 R / S)$-mixture eluted before the $(2 R$, $6 R / S, 10 R / S)$-mixture when derivatized as $(R)$-transchrysanthemoyl esters but eluted after the $(2 R, 6 R / S$, $10 R / S)$-mixture when derivatized as $(S)$-2-acetoxy-propionyl esters (See Figs. 1 and 2). The synthetic reference

Table 1 Identification of the peaks in the GC/MS chromatogram the (R)-trans-chrysanthemoyl ester of $(2 R / S, 6 S, 10 R)-6,10,14$ trimethylpentadecan-2-ol (1) with known stereoisomeric composition

\begin{tabular}{lll}
\hline Stereoisomer & $\begin{array}{l}\text { Calculated stereoisomer } \\
\text { content }^{\mathrm{a}}(\%)\end{array}$ & $\begin{array}{l}\text { Stereoisomer content by } \\
\text { GC/MS analysis }(\%)\end{array}$ \\
\hline$(2 S, 6 R, 10 S)$ & $0.5 \times 0.25 \times 0.43 \times 100=5$ & 5 \\
$(2 S, 6 R, 10 R)$ & $0.5 \times 0.25 \times 0.57 \times 100=7$ & 7 \\
$(2 S, 6 S, 10 R)$ & $0.5 \times 0.75 \times 0.57 \times 100=21$ & 23 \\
$(2 S, 6 S, 10 S)$ & $0.5 \times 0.75 \times 0.43 \times 100=16$ & 15 \\
$(2 R, 6 S, 10 R)$ & $0.5 \times 0.75 \times 0.57 \times 100=21$ & 24 \\
$(2 R, 6 S, 10 S)$ & $0.5 \times 0.75 \times 0.43 \times 100=16$ & 15 \\
$(2 R, 6 R, 10 S)$ & $0.5 \times 0.25 \times 0.43 \times 100=5$ & 5 \\
$(2 R, 6 R, 10 R)$ & $0.5 \times 0.25 \times 0.57 \times 100=7$ & 7 \\
\hline
\end{tabular}

${ }^{\text {a }}$ Using the stereoisomeric purities of the two building blocks 2 for C6 $(S / R 75: 25)$ and $\mathbf{3}$ for $\mathrm{C} 10(R / S 57: 43)$ samples $(2 R, 6 R, 10 R)$ - and $(2 S, 6 R, 10 R)-6,10,14$ trimethylpentadecan-2-ol also confirmed this elution order as (S)-2-acetoxypropionyl esters when compared with $(R)$-transchrysanthemoyl esters. One might speculate that the other stereoisomers of (S)-2-acetoxypropionyl esters may follow the same pattern of elution as the $(R)$-trans-chrysanthemoyl esters, but this was not tested.

Bicyclus Extracts The initial screening for 6,10,14trimethylpentadecan-2-ol and the corresponding ketone content in thirty-two Bicyclus species (Nieberding et al. unpublished data) resulted in a selection of 17 species (Table 2) that appeared to contain enough of the target compounds for stereochemical analysis. Raw extracts from the selected species were analyzed to quantify the amount of alcohol and ketone in all wing samples (Table 2). The method of derivatization was chosen based on the amount determined in the target compound in each sample. Derivatization with $(R)$ trans-chrysanthemoyl chloride proved to give the best GCseparation in the analysis of the reference samples but resulted in less pure samples when used for wing extract analysis. Consequently, this method was used when the wing samples contained relatively high amounts of 6,10,14trimethylpentadecan-2-ol and 6,10,14-trimethylpentadecan-2one, and the derivatization method with $(S)$-2-acetoxypropionyl chloride was used when the compounds were present in lower concentrations. The $(R)$-trans-chrysanthemoyl derivative of Bicyclus anynana wing extract was spiked with the $(2 R, 6 R / S$, $10 R / S$ )-mix (shown in Nieberding et al. 2008) to prove that the 
Table 2 Stereochemistry and amounts of 6,10,14-trimethylpentadecan-2-ol and 6,10,14-trimethyl-pentadecan-2-one in wing extracts from 17 African Bicyclus butterfly species as determined by

\begin{tabular}{|c|c|c|c|c|}
\hline $\begin{array}{l}\text { Bicyclus } \\
\text { species }\end{array}$ & $\begin{array}{l}\text { 6,10,14-Trimethyl- } \\
\text { pentadecan-2-ol }\end{array}$ & $\begin{array}{l}\text { 6,10,14-Trimethyl- } \\
\text { pentadecan-2-one }\end{array}$ & $\begin{array}{l}\text { Amount in } \\
\text { sample (ng) }\end{array}$ & Comment \\
\hline B. anisops & $(2 R, 6 R, 10 R)^{\mathrm{b}}$ & $(6 R, 10 R)$ & $300 / 900$ & partial wing \\
\hline B. anynana (2007) & $(2 R, 6 R, 10 R)^{\mathrm{b}, \mathrm{c}}$ & nd & 219 & whole wing \\
\hline B. anynana & $d^{b}$ & $(6 R, 10 R)^{\mathrm{d}}$ & $-/ 20$ & partial wing \\
\hline B. buea & nd & $(6 R, 10 R)^{\mathrm{d}}$ & 20 & partial wing \\
\hline B. dentata/ dentatus & nd & $(6 R, 10 R)$ & 60 & partial wing \\
\hline B. dorothea & nd & $\mathrm{d}$ & 5 & whole wing \\
\hline B. ephorus & $(2 R, 6 R, 10 R)^{\mathrm{b}, \mathrm{c}}$ & nd & 70 & partial wing \\
\hline B. golo & nd & $(6 R, 10 R)$ & 80 & whole wing \\
\hline B. graueri & $(2 R, 6 R, 10 R)^{\mathrm{c}}$ & nd & 20 & trace, partial wing \\
\hline B. heteropsis peitho & nd & $\mathrm{d}$ & 5 & partial wing \\
\hline B. ignobilis & $d^{2}$ & nd & 25 & partial wing \\
\hline B. mandanes & nd & $(6 R, 10 R)$ & 130 & trace, whole wing \\
\hline B. mollitia & $(2 R, 6 R, 10 R)^{\mathrm{c}}$ & $\mathrm{d}$ & - & partial wing \\
\hline B. safitza & $(2 R, 6 R, 10 R)^{\mathrm{b}}$ & nd & 100 & partial wing \\
\hline B. sambulos & nd & $(6 R, 10 R)$ & 150 & partial wing \\
\hline B. sandace & nd & $(6 R, 10 R)$ & 95 & whole wing \\
\hline B. sebetus & $(2 R, 6 R, 10 R)^{\mathrm{c}}$ & $\mathrm{d}$ & $30 /-$ & $\begin{array}{c}\text { reconcentrated, } \\
\text { whole wing }\end{array}$ \\
\hline B. vulgaris & nd & $(6 R, 10 R)$ & 700 & partial wing \\
\hline
\end{tabular}

a Analyzed as (S)-2-acetoxypropionyl ester after reduction to alcohol

b Analyzed as (R)-trans-chrysanthemoyl ester

c Analyzed as (S)-2-acetoxypropionyl ester

d Amount close to the detection limit

extract contained $(2 R, 6 R / S, 10 R / S)$-alcohol. Recently we also determined that the stereochemistry of the secondary alcohol in $B$. anynana was $(2 R, 6 R, 10 R)-6,10,14$-trimethylpentadecan-2ol (Nieberding et al. 2012). All 17 wing extracts were analyzed with one or both methods (Table 2), and seven species showed $(2 R, 6 R, 10 R)$-configuration of the $6,10,14$ trimethylpentadecan-2-ol, four species contained amounts of alcohol too small to determine the stereochemistry, nine species showed $(6 R, 10 R)$-configuration of the corresponding ketone, and one species contained amounts of ketone too small to determine the stereochemistry (Table 2). No other stereoisomers of alcohol or ketone could be detected in the extracts.

The butterfly Pieris brassicae produces 6,10,14trimethylpentadecan-2-ol from natural intake of nutrition (Schulz et al. 2011). Our study of the 17 Bicyclus species showed that only $(2 R, 6 R, 10 R)-6,10,14$-trimethylpentadecan2-ol and/or $(6 R, 10 R)-6,10,14$-trimethylpentadecan-2-one were present in the wing samples. The occurrence in all the species of the same stereoisomers of the two compounds, with rather complex structures that can have eight
GC/MS analyses of derivatized samples (nd not detected; $\mathrm{d}$ detected but amount too small to determine stereochemistry or quantity reliably) 


\section{References}

Anderbrant, O (1999) Sawflies and seed wasps. In: Hardie J, Minks AK (eds) Pheromones of non-Lepidopteran insects associated with agricultural plants. CABI Publishing, pp 199-226

Anderbrant $\mathrm{O}$, Löfqvist J, Högberg H-E, Hedenström E, Baldassari N, Baronio P, Kolmakova G, Lyons B, Naito T, Odinokov V, Simandl J, Supatashvili A, Tai A, Tourianov R (2000) Geographic variation in the field response of male European Pine Sawflies, Neodiprion sertifer, to different pheromone stereoisomers and esters. Entomol Exp Appl 95:229-239

Ashby EC, Lin JJ (1978) Selective reduction of alkenes and alkynes by the reagent lithium aluminum hydride-transition-metal halide. J Org Chem 43:2567-2572

Bång J, Hedenström E, Sjödin K (2011) Purification, stereoisomeric analysis and quantification of sex pheromone precursors in female whole body extracts from pine sawfly species. J Chem Ecol 37:125-133

Bång J, Hedenström E, Anderbrant O (2012) Stereoisomeric separation of derivatized 2-alkanols using gas chromatography-mass spectrometry: sex pheromone precursors found in pine sawfly species. Anal Lett 45:1016-1027

Bergström $\mathrm{G}$, Wassgren $\mathrm{AB}$, Anderbrant $\mathrm{O}$, Fägerhag J, Edlund $\mathrm{H}$, Hedenström E, Högberg H-E, Geri C, Auger MA, Varama M, Hansson BS, Löfqvist J (1995) Sex-pheromone of the pine sawfly Diprion pini (Hymenoptera, Diprionidae) - chemical identification, synthesis and biological activity. Experientia 51:370-380

Burger BV, Nell AE, Smit D, Spies HSC, Mackenroth WM, Groche D, Atkinson PR (1993) Constituents of wing gland and abdominal hairpencil secretions of male African sugarcane borer, Eldana saccharina Walker (Lepidoptera, Pyralidae). J Chem Ecol 19: 2255-2277

Burns DH, Millar JD, Chan H-K, Delaney MO (1997) Scope and utility of a new soluble copper catalyst [CuBr-LiSPh-LiBr-THF]: A comparison with other copper catalysts in their ability to couple one equivalent of Grignard reagent with an alkyl sulfonate. J Am Chem Soc 119:2125-2133

Enders D, Schüsseler T (2002) Asymmetric synthesis of all stereoisomers of 7,11-dimethylheptadecane and 7-methylheptadecane, the female pheromone components of the spring hemlock looper and the pitch pine looper. Tetrahedron Lett 43:3467-3470

Hall DR, Cork A, Lester R, Nesbitt BF, Zagatti P (1987) Sex-pheromones of rice moth, Corcyra cephalonica Stainton.2. Identification and role of female pheromone. J Chem Ecol 13:1575-1589

Hedenström E, Nguyen B-V, Silks LA III (2002) Do enzymes recognise remotely located stereocentres? Highly enantioselective Candida rugosa lipase-catalysed esterification of the 2- to 8-methyldecanoic acids. Tetrahedron Asymmetry 13:835-844

Högberg H-E, Hedenström E, Fägerhag J, Servi S (1992) Bakers' yeast reduction of thiophenepropenals. Enantioselective synthesis of (S)2-methyl-1-alkanols via bakers' yeast mediated reduction of 2-methyl-3-(2-thiophene)propenals. J Org Chem 57:2052-2059

Kandula SRV, Kumar P (2006) An asymmetric aminohydroxylation route to cis-2,6-disubstituted piperidine-3-ol: application to the synthesis of (-)-deoxocassine. Tetrahedron 62:9942-9948

Kimura T, Carlson DA, Mori K (2001) Synthesis of all the stereoisomers of 13,17-dimethyl-1-tritriacontene and 13,17-dimethyl-1pentatriacontene, the contact sex pheromone components of the female tsetse fly, Glossina austeni. Eur J Org Chem 2001:33853390

Mori K, Harada H, Zagatti P, Cork A, Hall DR (1991) Pheromone synthesis, CXXVI. Synthesis and biological activity of four stereoisomers of 6,10,14-trimethyl-2-pentadecanol, the female-produced sex pheromone of rice moth (Corcyra cephalonica). Liebigs Ann Chem 3:259-267

Nagamitsu T, Sunazuka T, Tanaka H, Omura S, Sprengeler PA, Smith AB (1996) Total synthesis of (+)-Lactacystin. J Am Chem Soc 118: 3584-3590

Nakamura Y, Mori K (2000) New synthesis of the rice moth and stink bug pheromones by employing $(2 \mathrm{R}, 6 \mathrm{~S})-7$-acetoxy-2,6dimethyl-1-heptanol as a building block. Biosci Biotechnol Biochem 64:1713-1721

Nieberding CM, de Vos H, Schneider MV, Lassance JM, Estramil $\mathrm{N}$, Andersson $\mathrm{J}$, Bång $\mathrm{J}$, Hedenstrom E, Löfstedt $\mathrm{C}$, Brakefield PM (2008) The male sex pheromone of the butterfly Bicyclus anynana: towards an evolutionary analysis. PLoS One 3:e2751

Nieberding CM, Fischer K, Saastamoinen M, Allen CE, Wallin EA, Hedenström E, Brakefield PM (2012) Cracking the olfactory code of a butterfly: the scent of ageing. Ecol Lett 15: 415-424

Sabbani S, Hedenström E, Nordin O (2006) The enantioselectivity of Candida rugosa lipase is influenced by the particle size of the immobilising support material Accurel. J Mol Catal B Enzym 42: $1-9$

Salimova EV, Kukovinets OS, Kasradze VG, Galin FZ, Kuchin AV, Koroleva AA (2003) Oxidative transformations of polyprenols. Chem Nat Comp 39:303-306

Sasaerila Y, Gries R, Khaskin G, King S, Takakcs S, Hardi (2003) Sex pheromone components of male Tirathaba mundella (Lepidoptera: Pyralidae). Chemoecology 13:89-93

Schulz S, Yildizhan S, van Loon JJA (2011) The biosynthesis of hexahydrofarnesylacetone in the butterfly Pieris brassicae. J Chem Ecol 37:360-363

Shibata C, Furukawa A, Mori K (2002) Synthesis of racemic and diastereomeric mixtures of 3,7,11,15-tetramethylhentriacontane and 4,8,12,16-tetramethyldotriacontane, the cuticular tetramethylalkanes of the tsetse fly, Glossina brevipalpis. Biosci Biotechnol Biochem 66:582-587

Umbreit MA, Sharpless KB (1977) Allylic oxidation of olefins by catalytic and stoichiometric selenium dioxide with tert-butyl hydroperoxide. J Am Chem Soc 99:5526-5528

Wassgren $\mathrm{AB}$, Anderbrant $\mathrm{O}$, Löfqvist J, Hansson BS, Bergström G, Hedenström E, Högberg H-E (1992) Pheromone relatedcompounds in pupal and adult female Pine Sawflies, Neodiprion sertifer, of different age and different parts of the body. J Insect Physiol 38:885-893 